
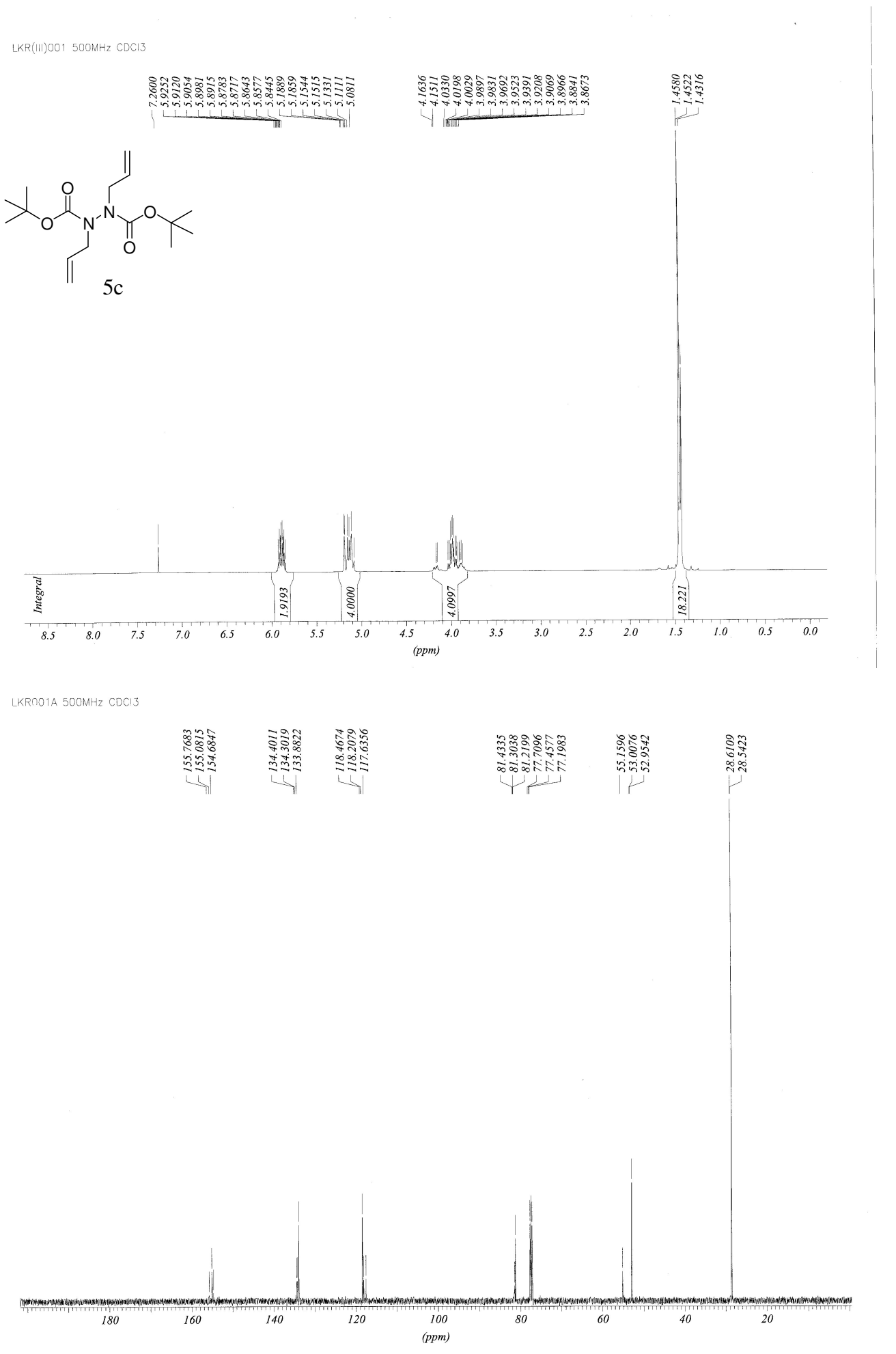


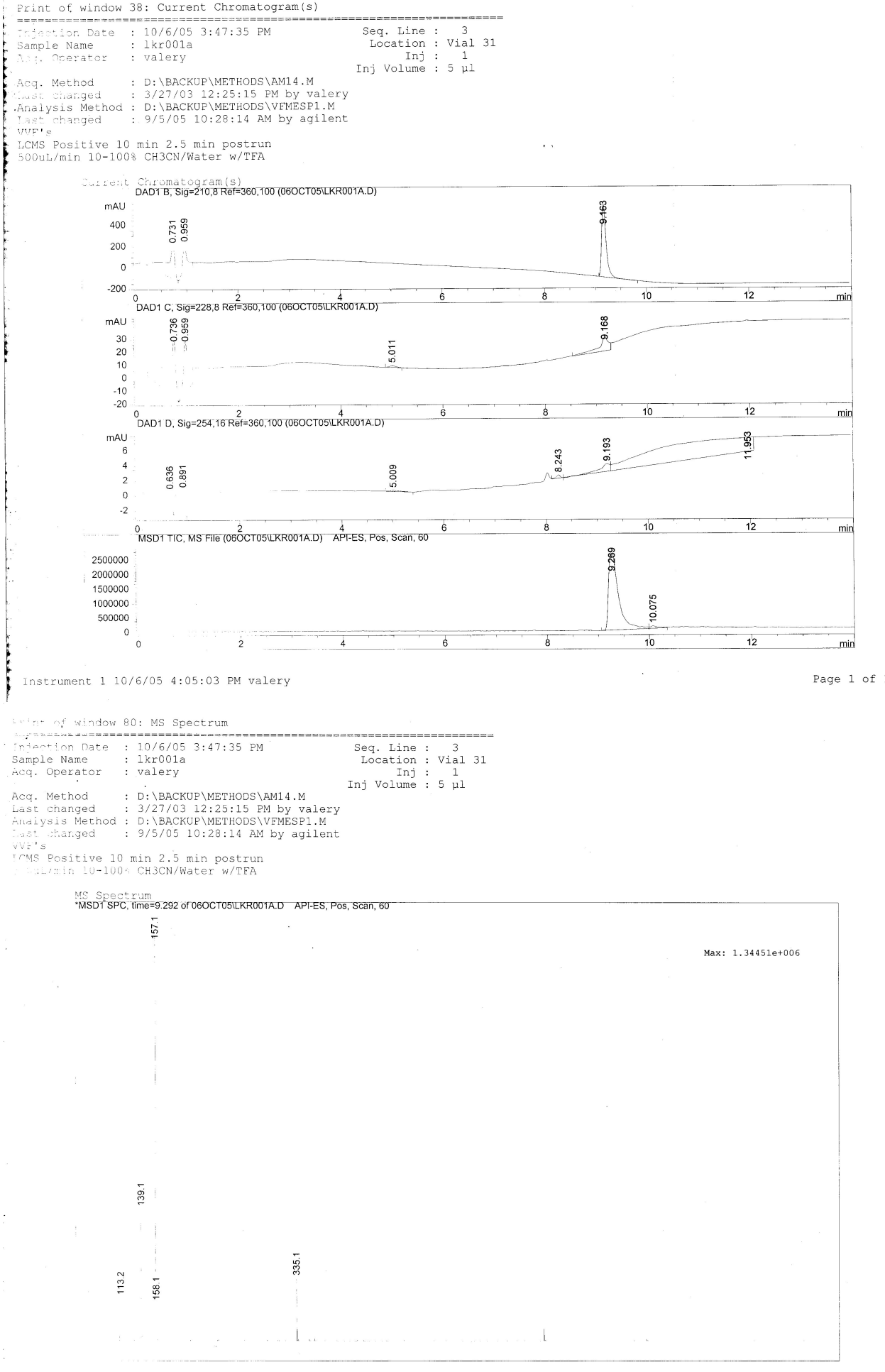


. LKR \{ill)0020 CDC13 600MHz 500C

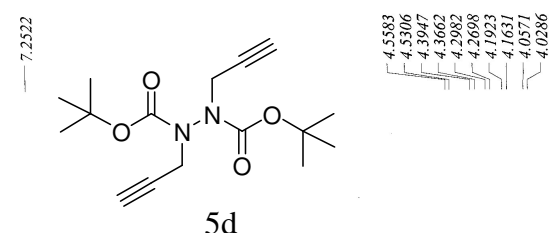

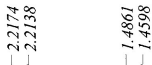

$5 d$

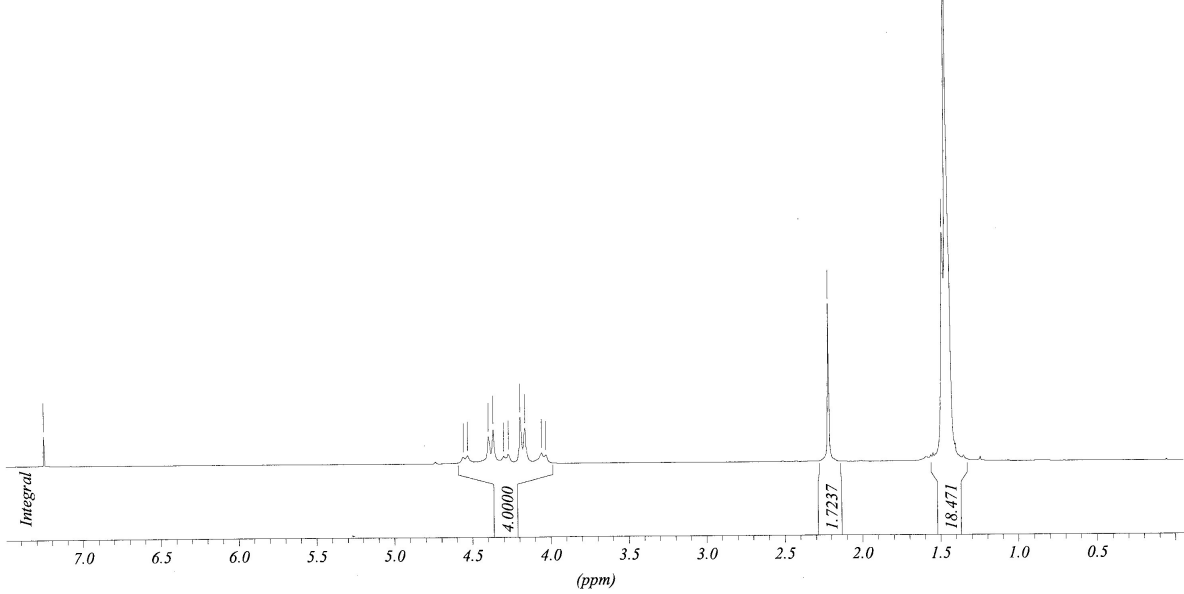

LKR $(111) 002 a$ CDCl3 600MHz 5000

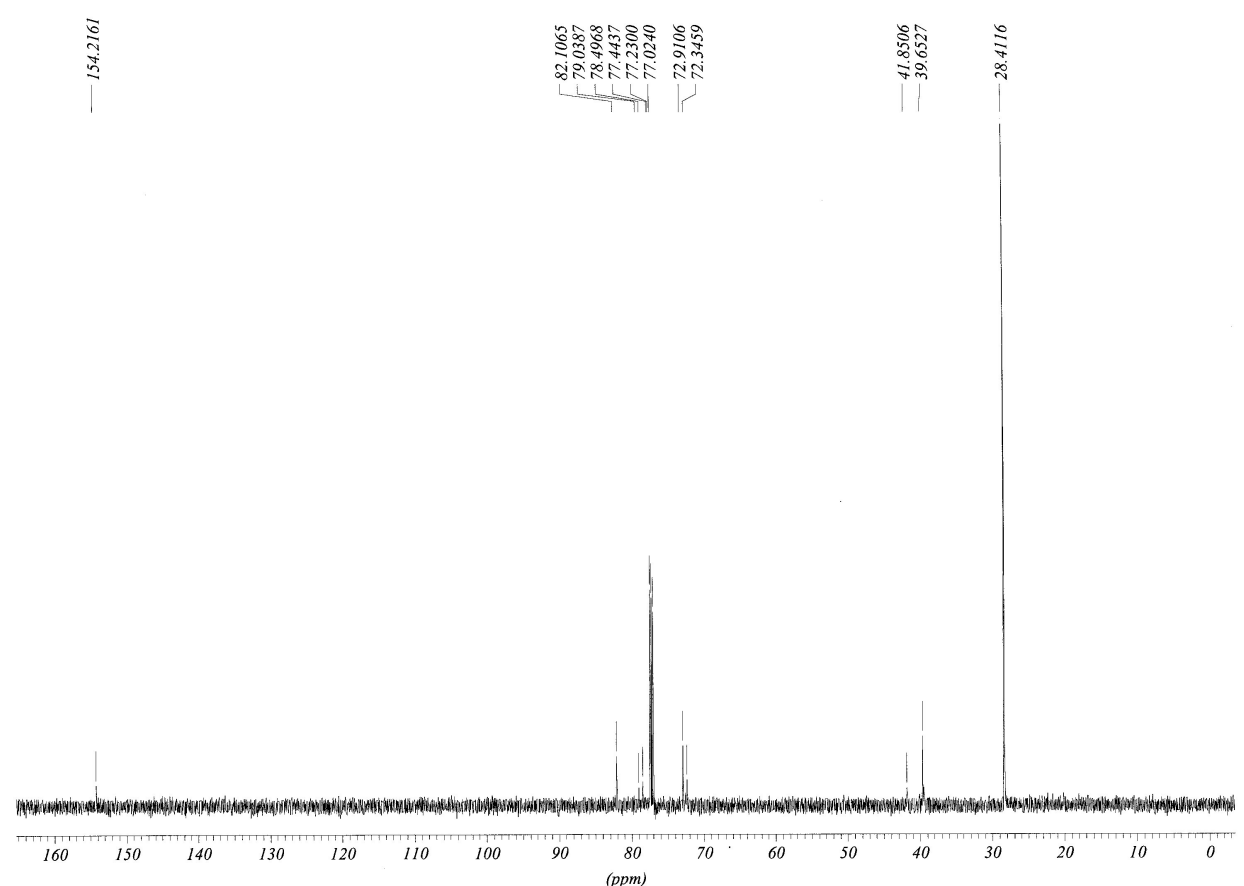




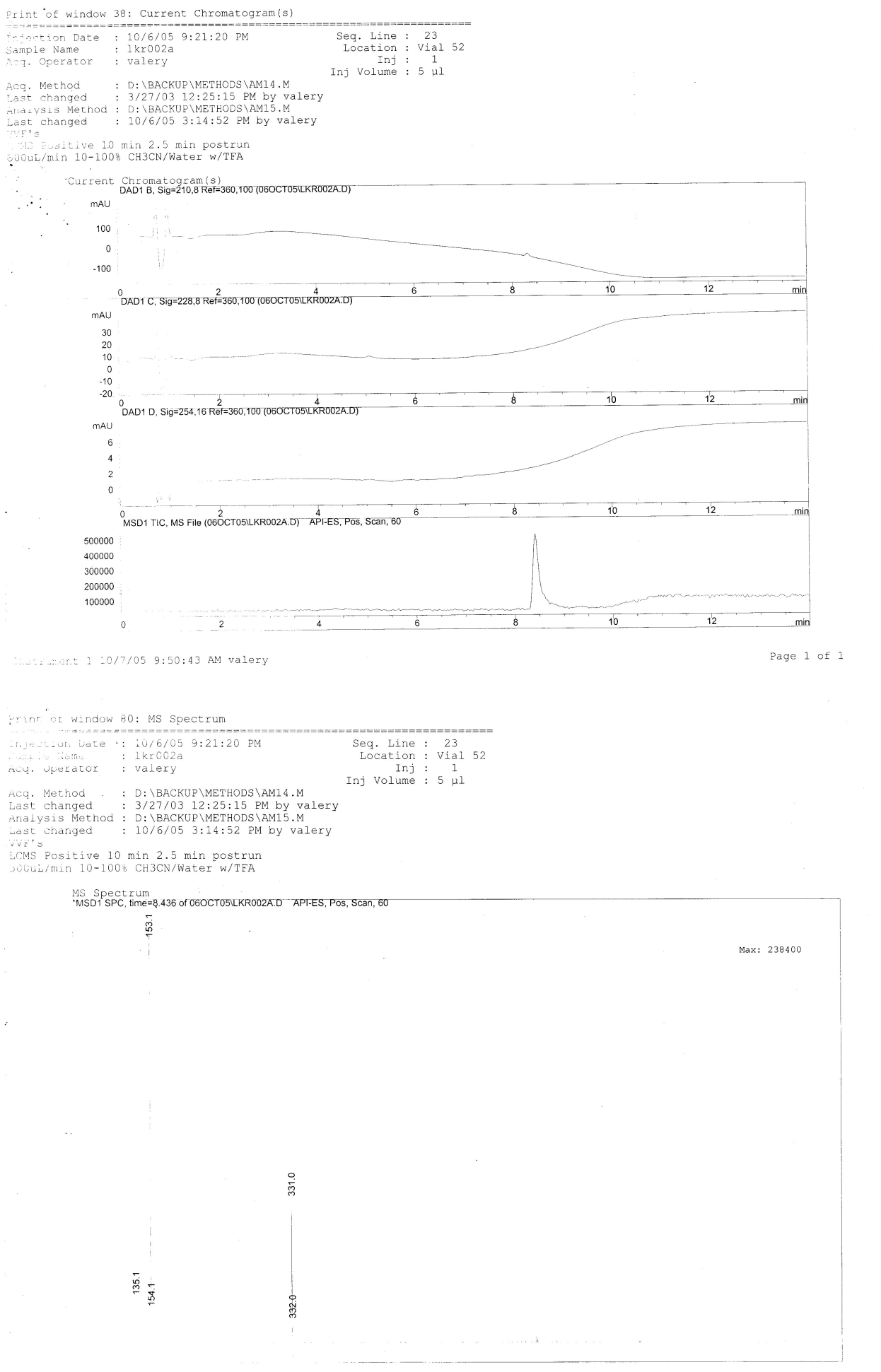




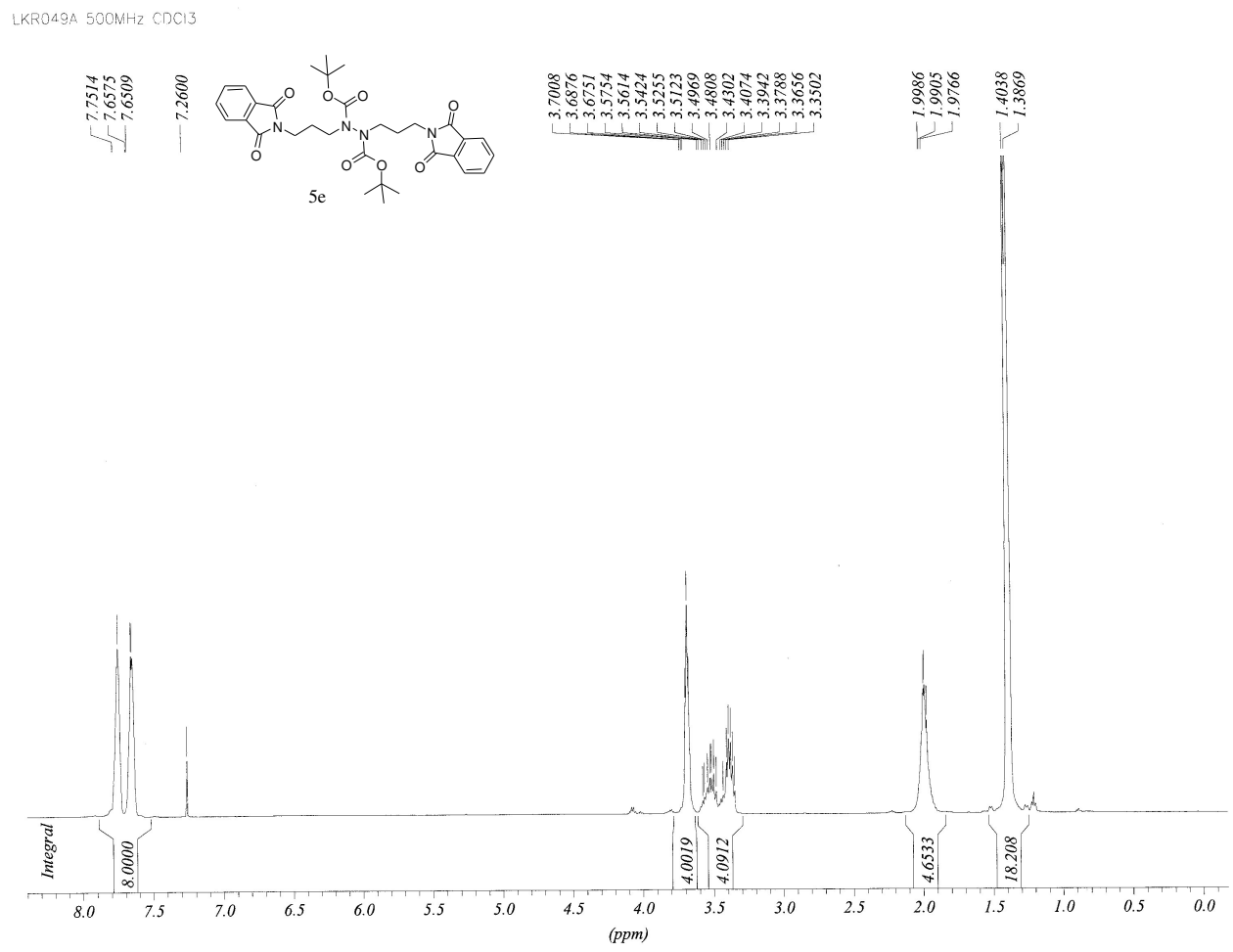

LLKR049A 50OMHZ CDC13
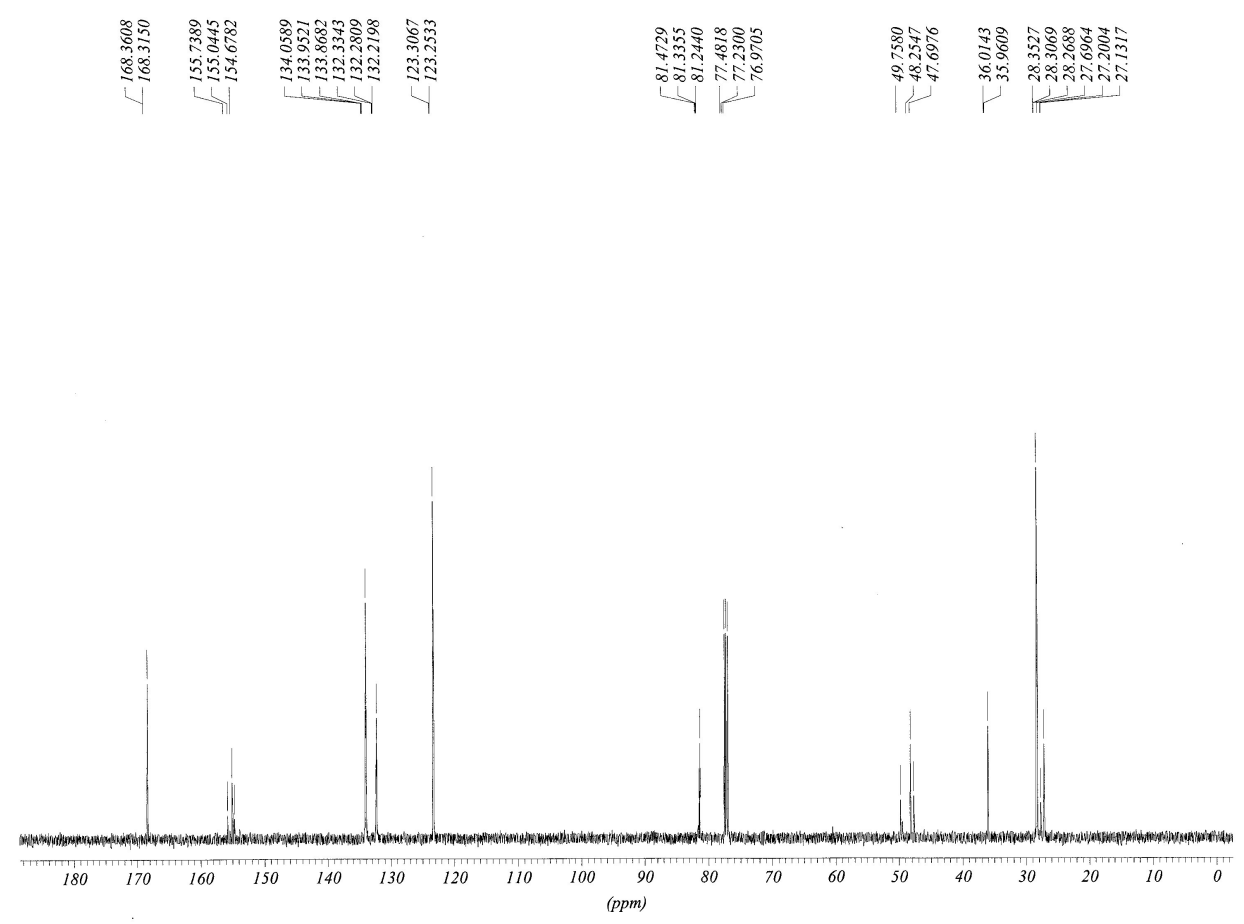
rint of window 38: Current Chromatogram (s)
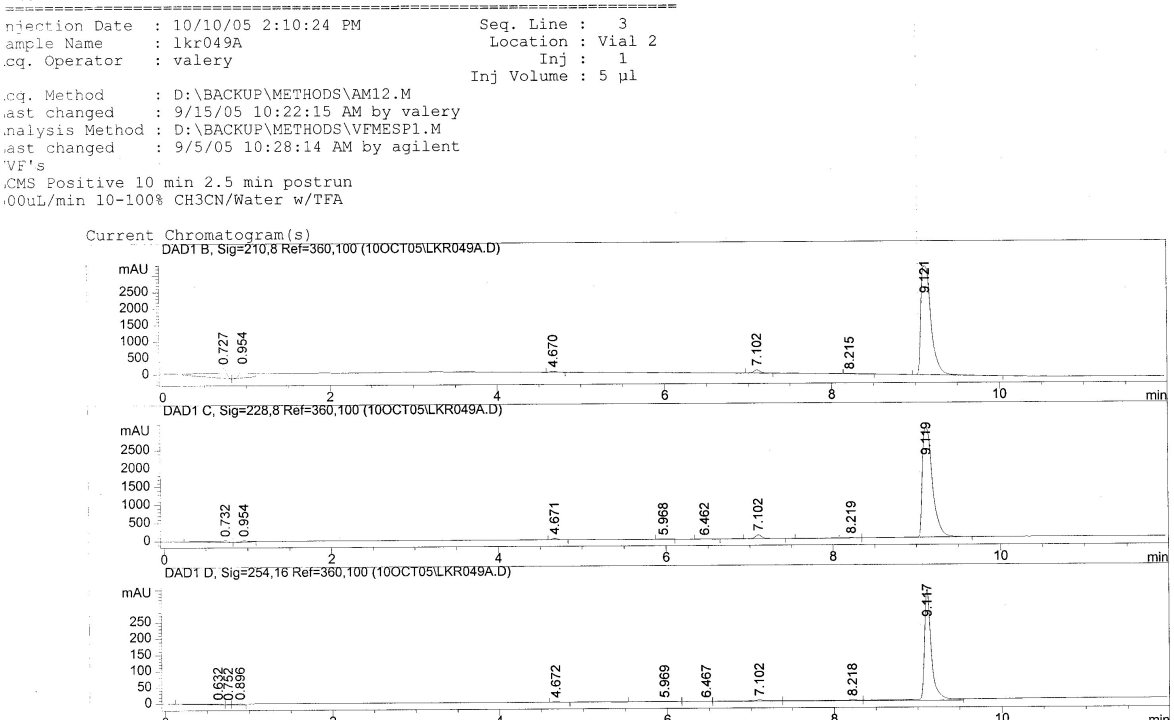

MSD1 TIC, MS File (100CTO5LLKR049A.D) API-ES, PoS, Scan, $60 \quad 60$

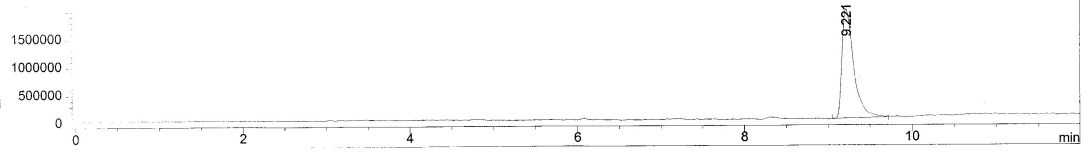

Instrument 1 10/10/05 2:30:09 PM valery

Page 1 of 1

A... Window 00: MS Spectrum

\begin{tabular}{|c|c|c|}
\hline $\begin{array}{l}\text { Injection Date } \\
\text { Sample Name } \\
\text { Acq. Operator }\end{array}$ & $\begin{array}{l}10 / 10 / 05 \quad 2: 10: 24 \text { PM } \\
1 \mathrm{kr049 \textrm {A }} \\
\text { : valery }\end{array}$ & 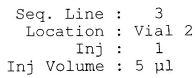 \\
\hline 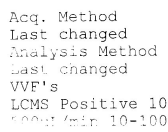 & 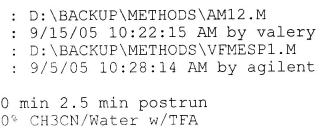 & \\
\hline
\end{tabular}

LCMS Positive 10 min 2.5 man postru

MS Spect rum
"MSD1 SPC, time $=9.198: 9.268$ of 100CT05LKRO49A.D API-ES, Pos, Scan, 60

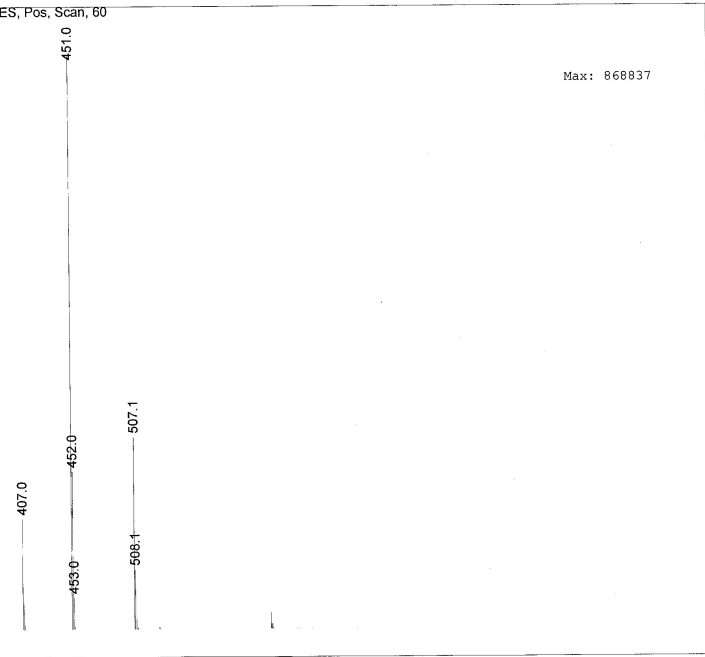


LKRO33A 500MHZ CDCl3

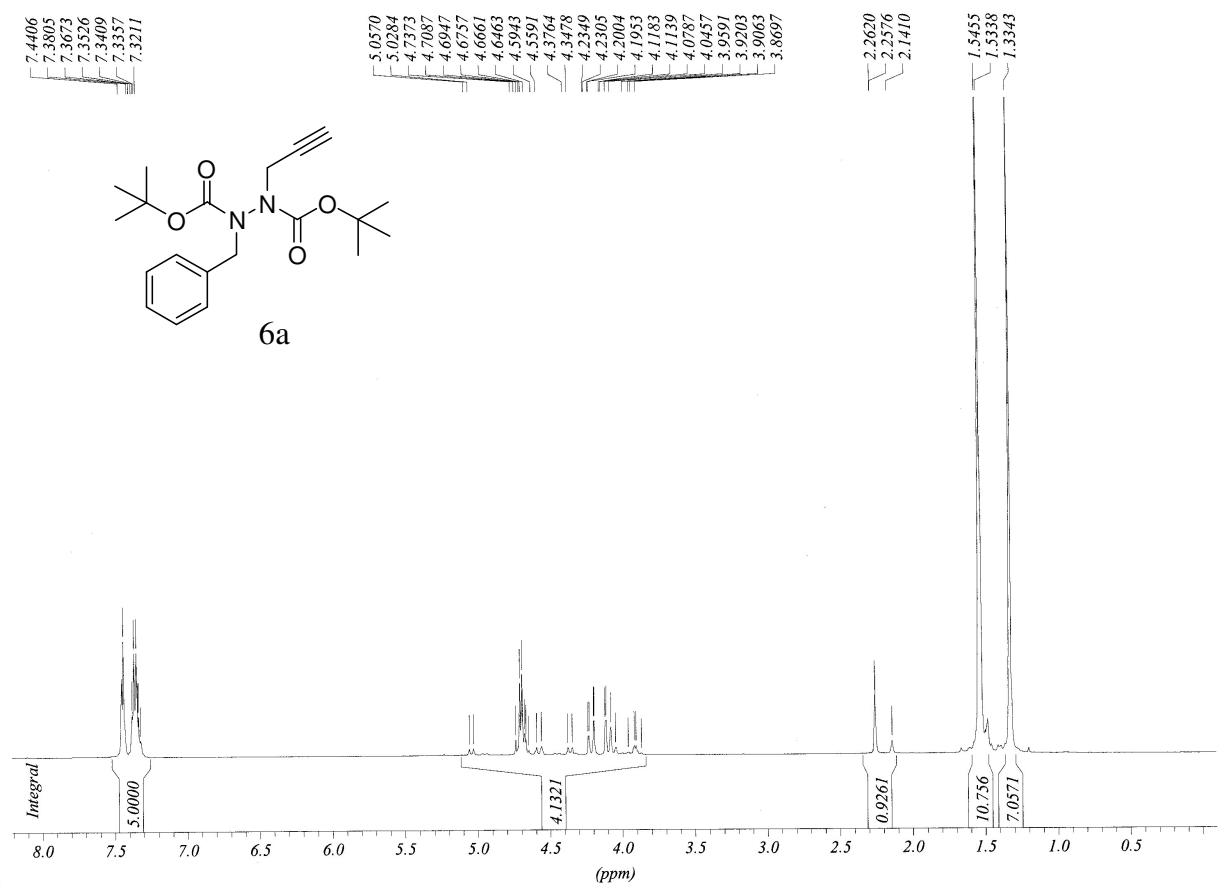

LKR033A 500MHz CDCl3
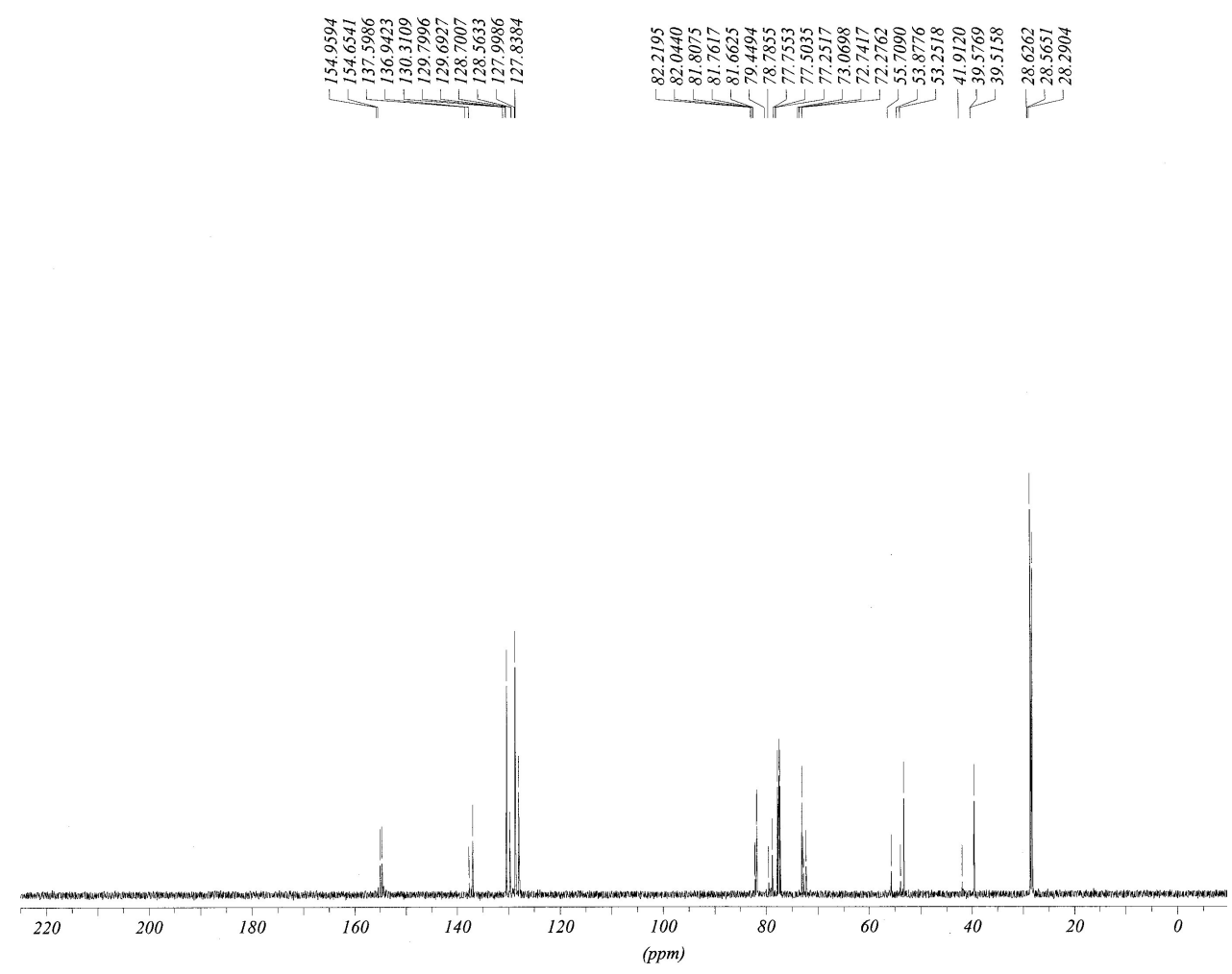


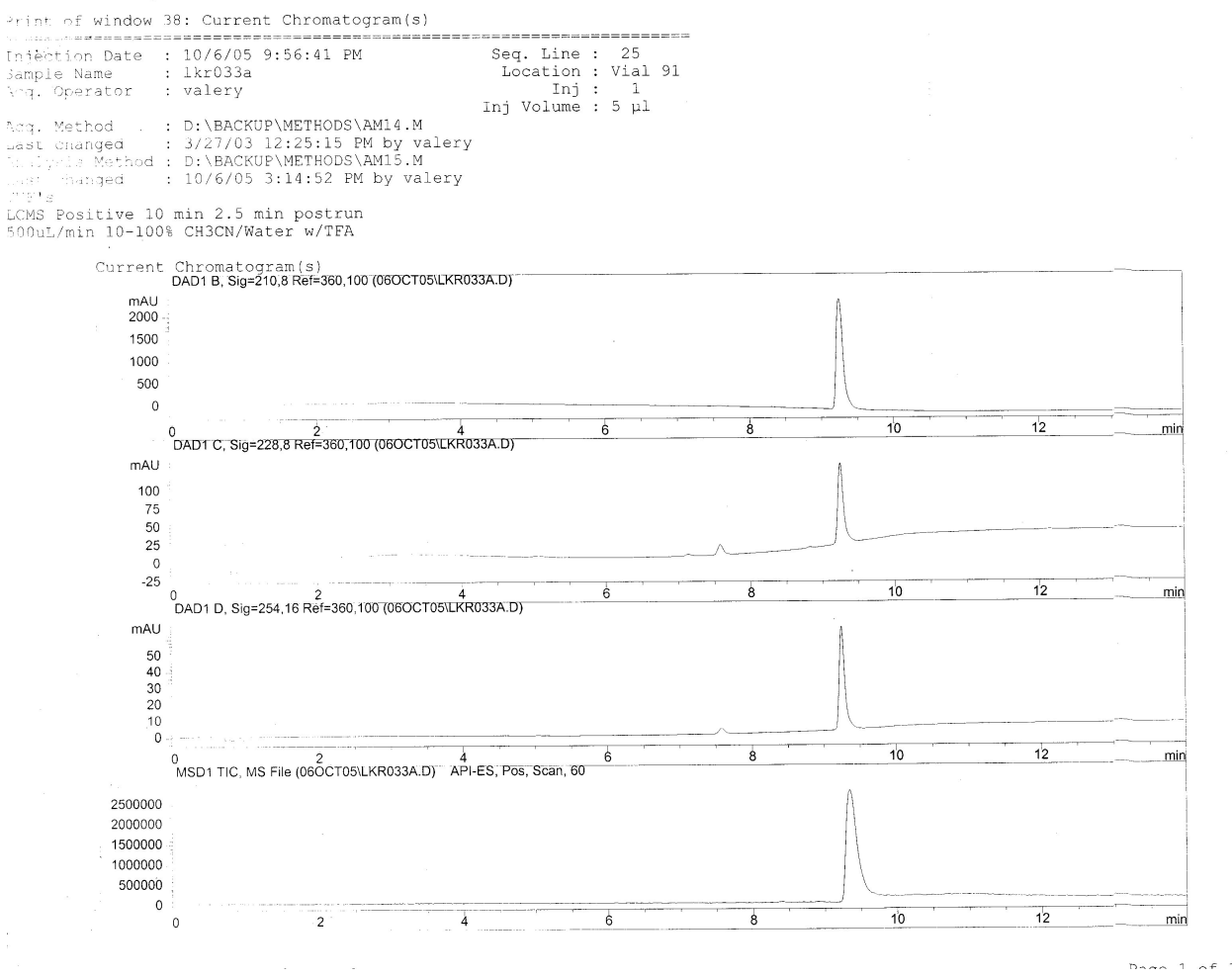

Print of window 80: MS Spectrum
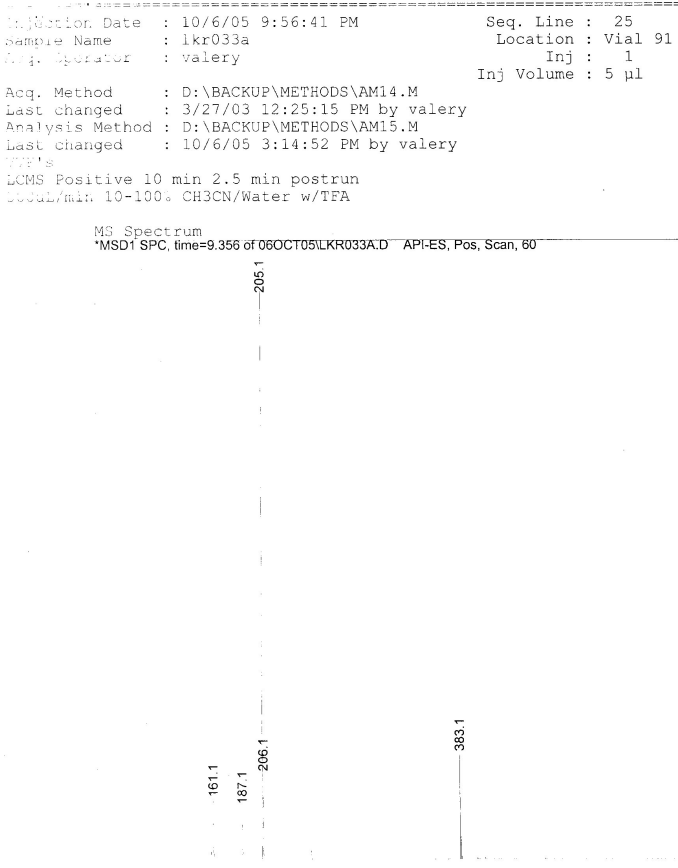


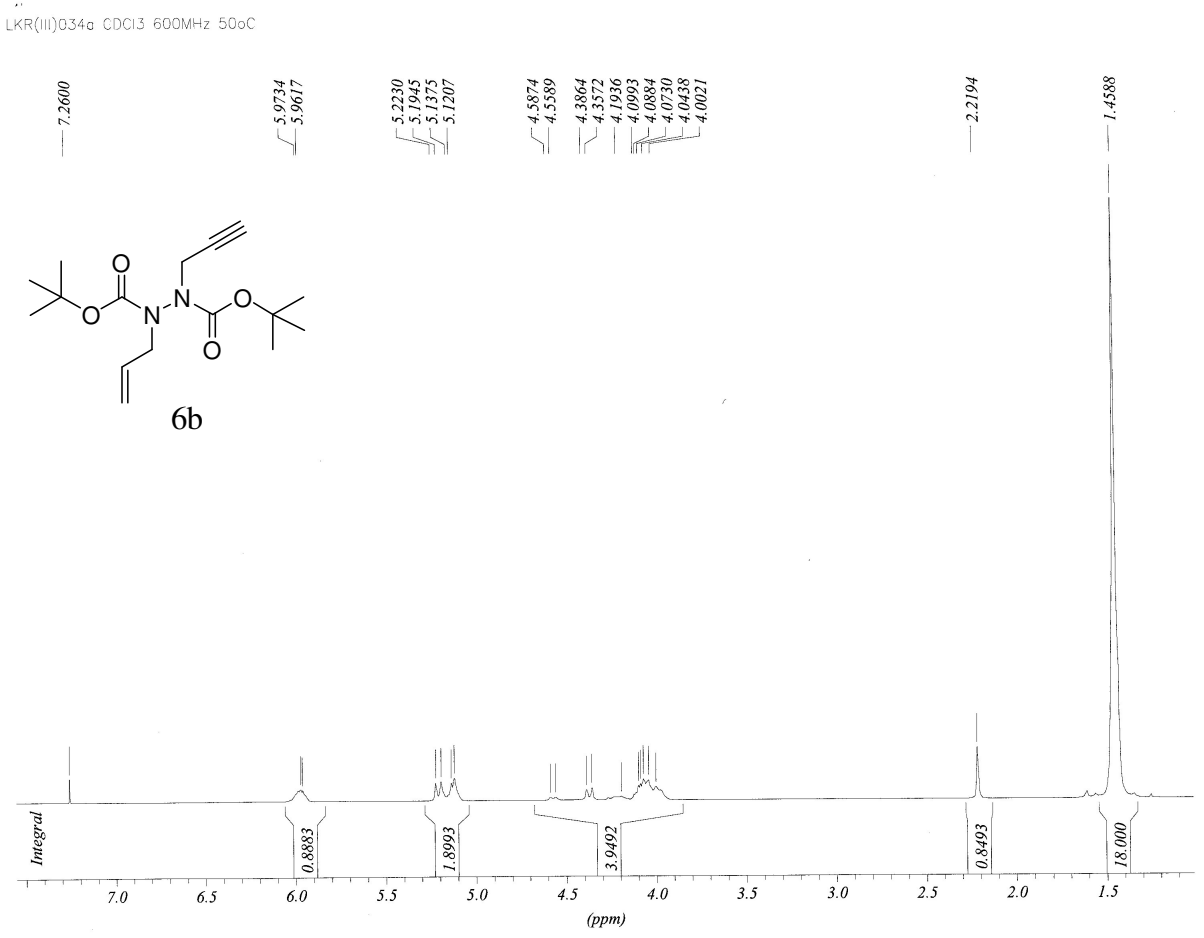

LKR(HII)0340 CDC13 600MHz 500C

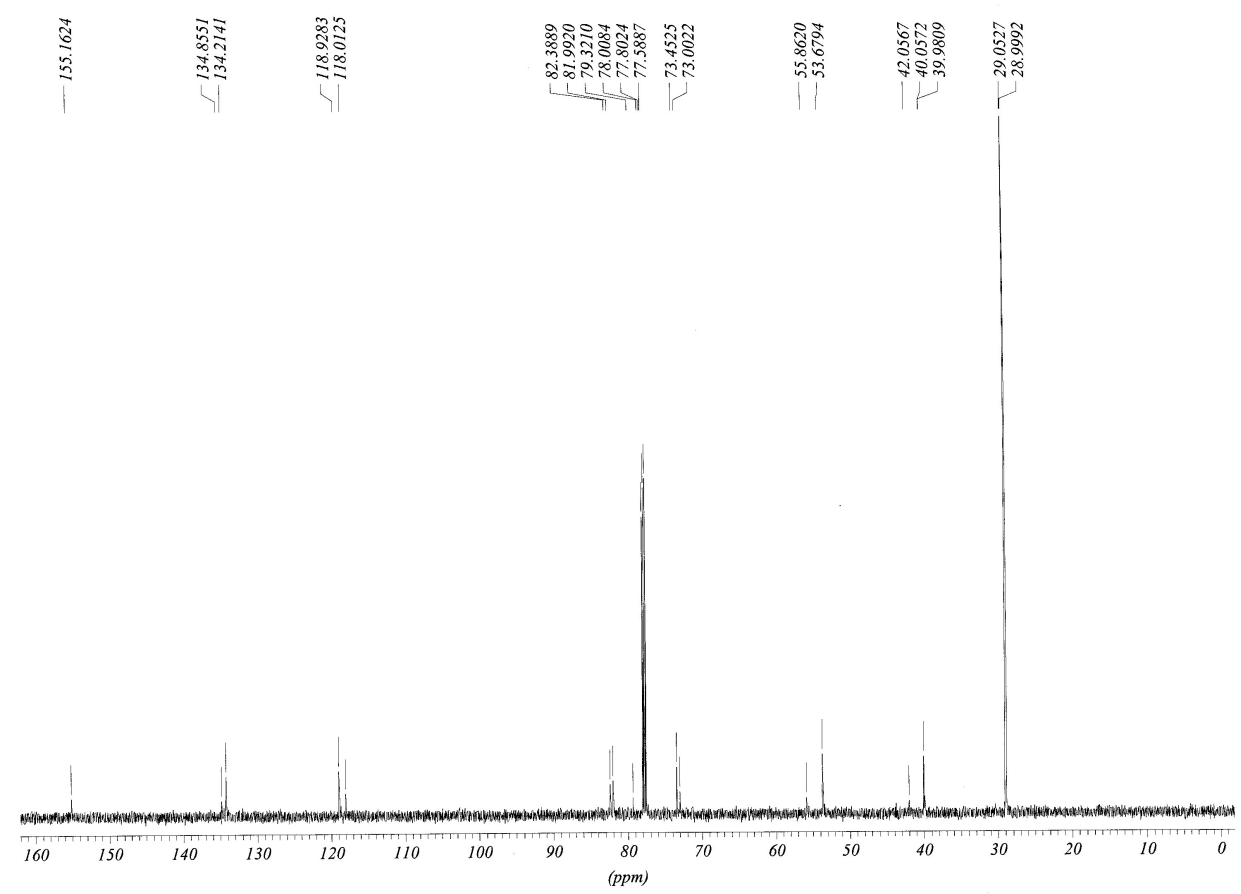




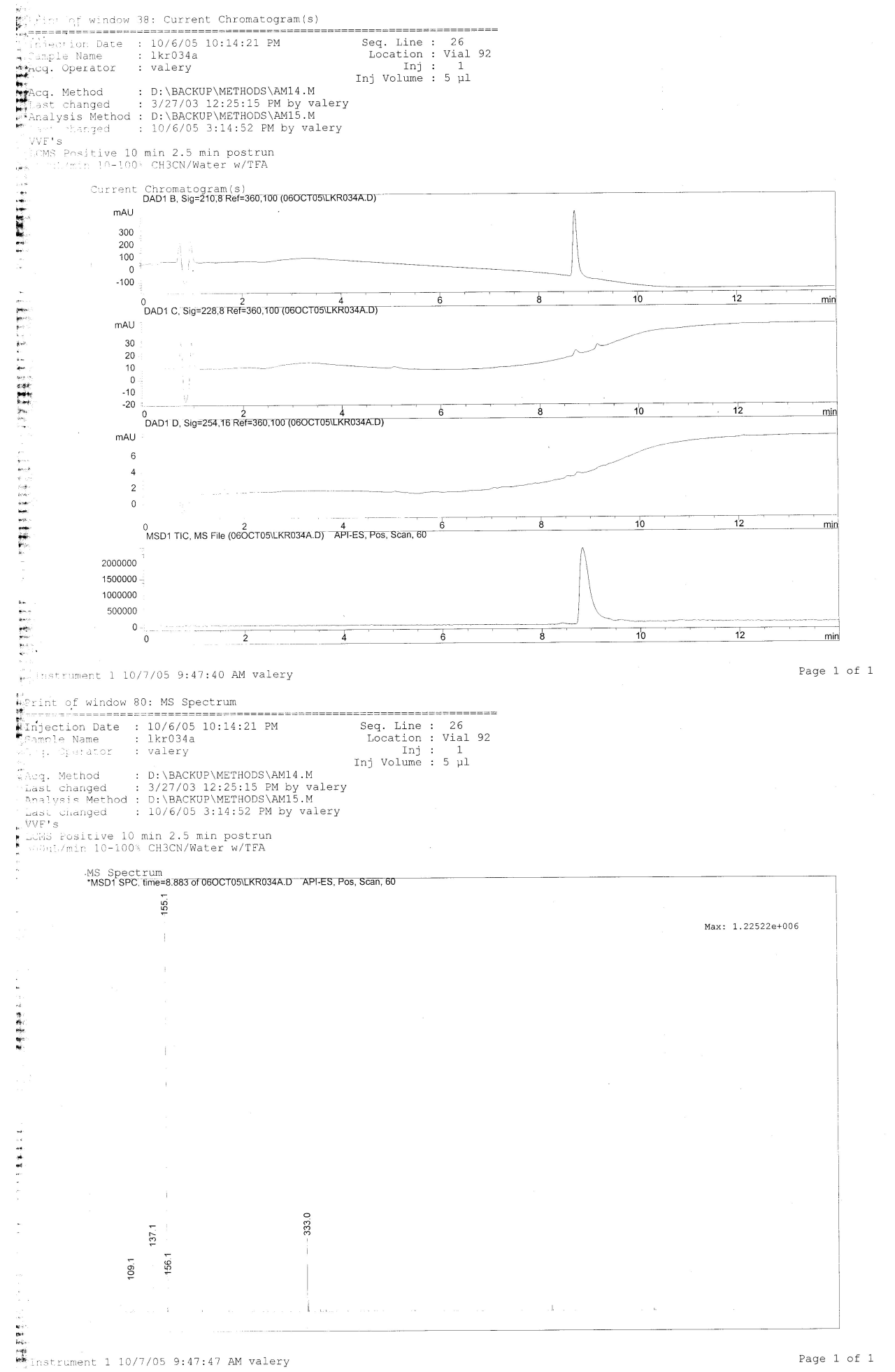




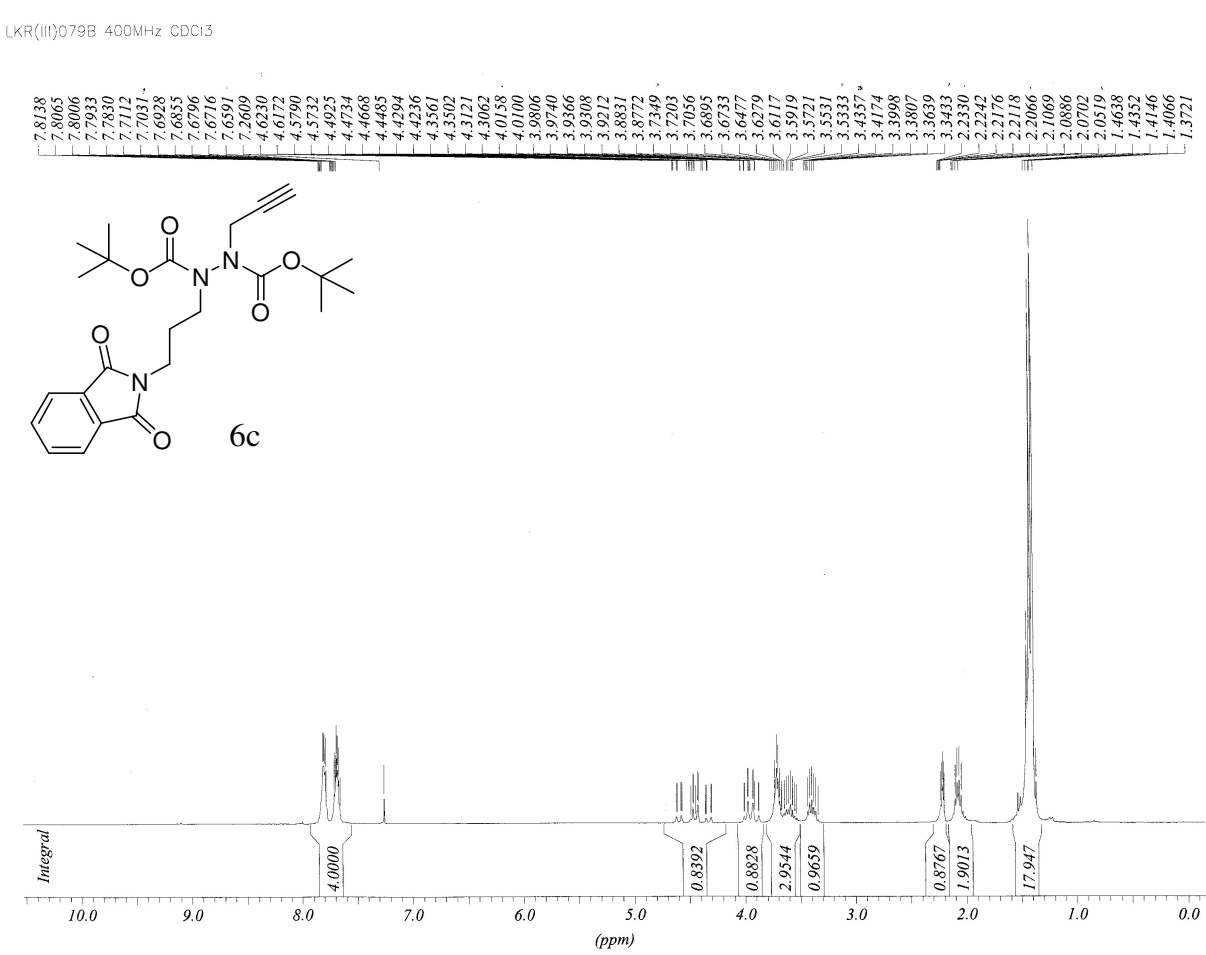

LKR(III)079B 400MHz CDCI3

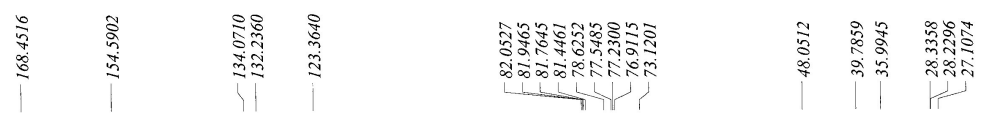

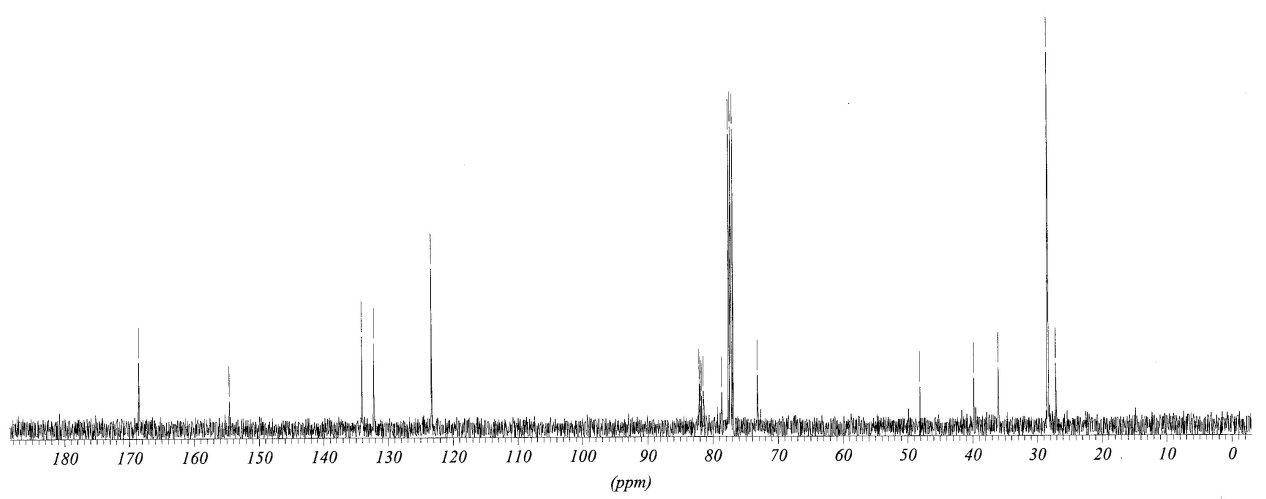




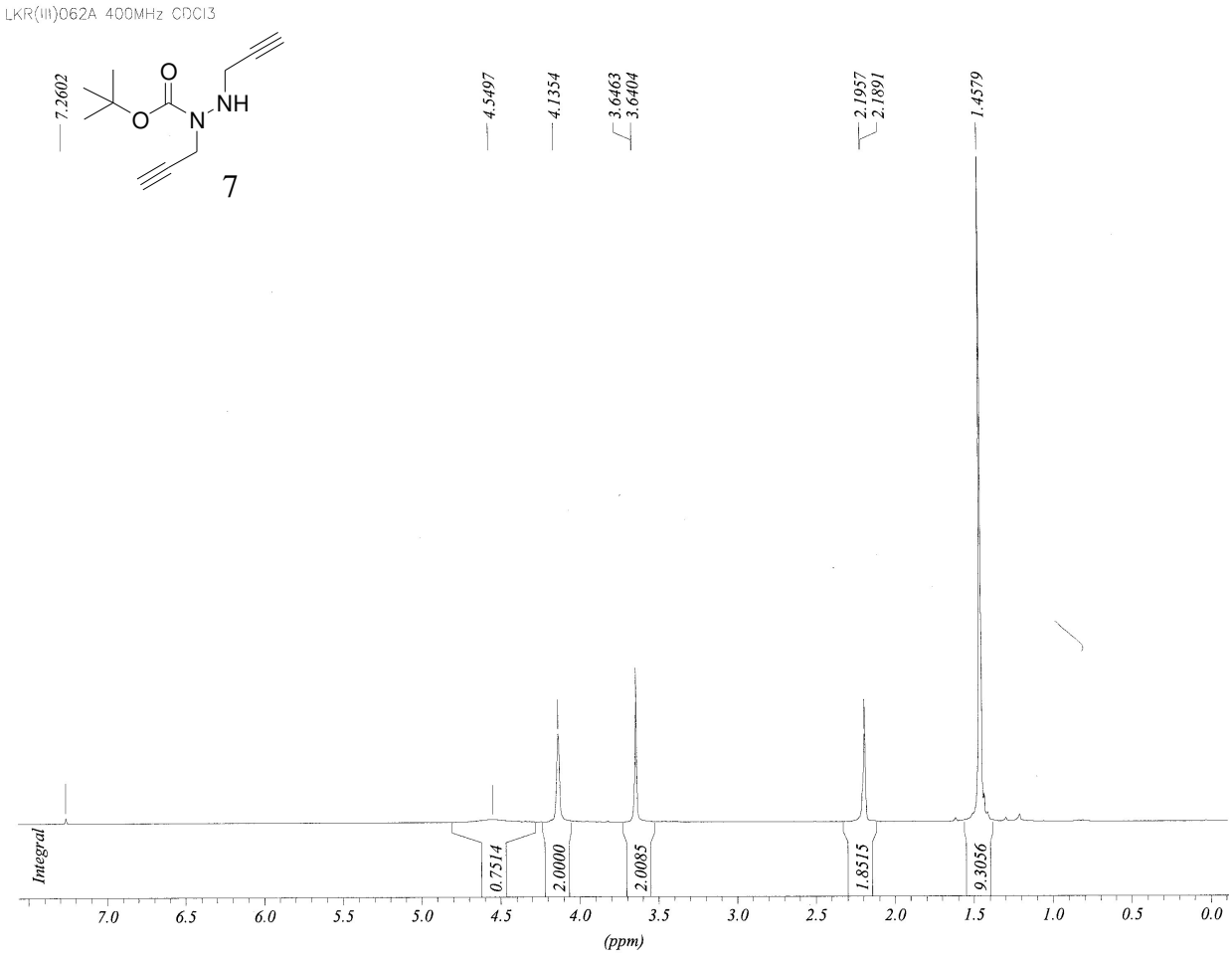

LKR(III)062A 400MHZ CDCI3

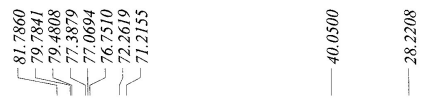

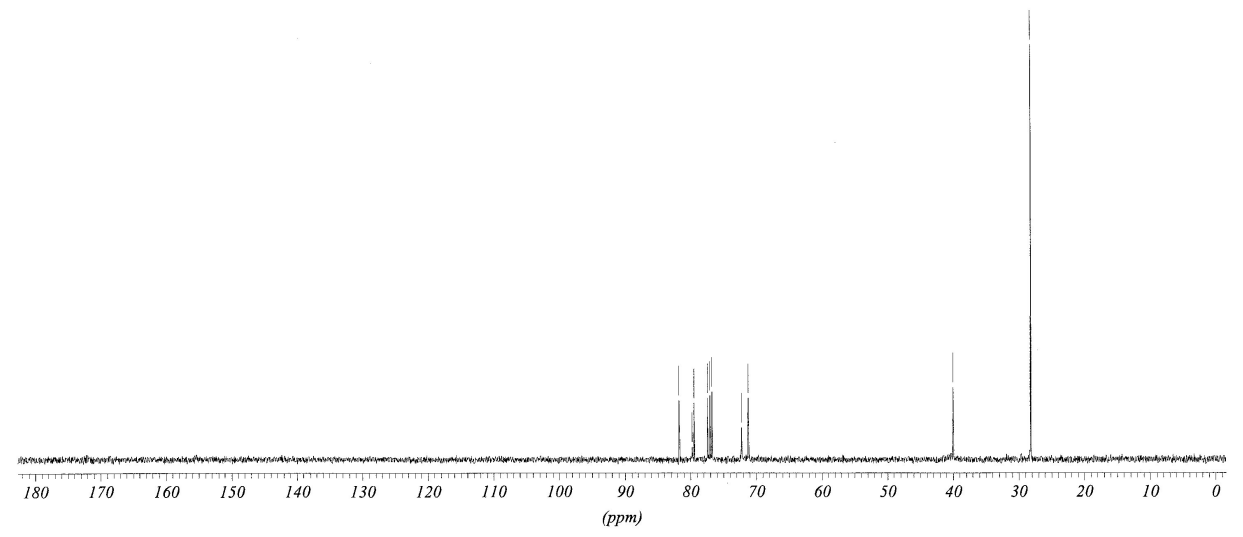




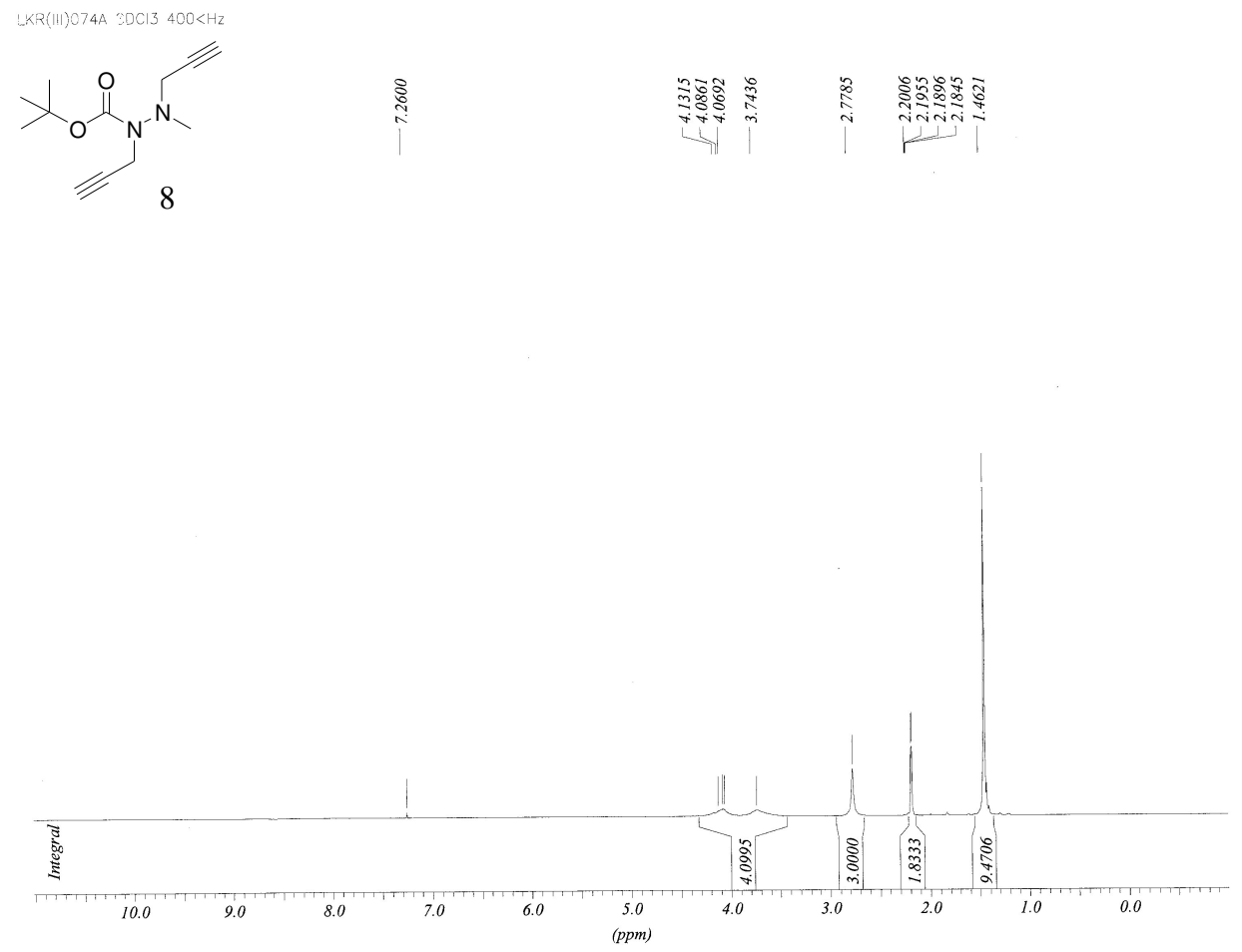

LKRIIII)074A CDCl3 400<Hz

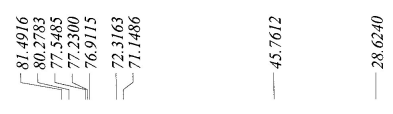

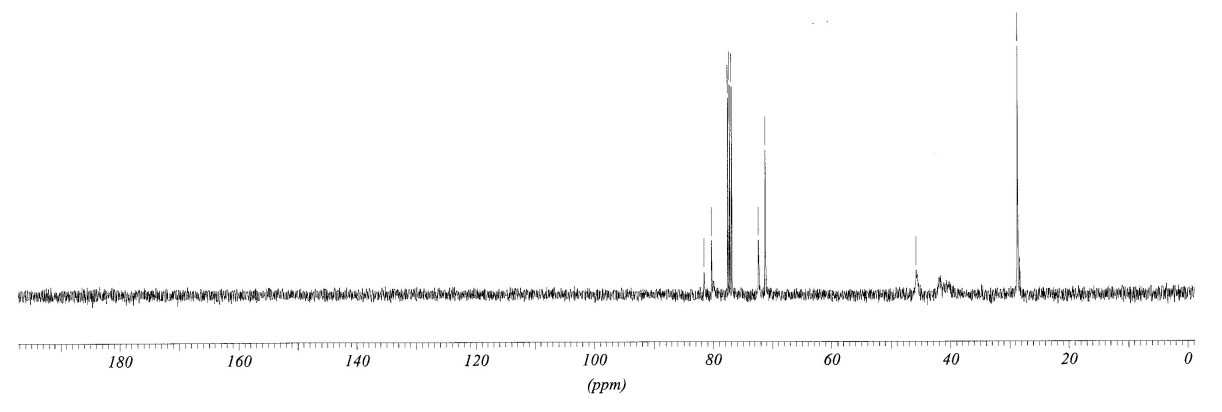




\section{Reference List}

1. Maeorg, U.; Pehk, T.; Ragnarsson, U. Acta Chem. Scand. 1999, 53, 1127-1133.

2. Maeorg, U.; Grehn, L.; Ragnarsson, U. Ang. Chem. Int. Ed. 1996, 35, 2626-2627.

3. Ling, L.; Urichuk, L. J.; Sloley, B. D.; Coutts, R. T.; Baker, G. B.; Shan, J. J.; Pang, P. K. T. Bioorg. Med. Chem. Lett. 2001, 11, 2715-2717.

4. Maeorg, U.; Ragnarsson, U. Tetrahedron Lett. 1998, 39, 681-684. 